\title{
ANALISIS GARIS SEMPADAN BANGUNAN (STUDI KASUS JALAN RAYA PAJAJARAN KOTA BOGOR)
}

\author{
(Analysis Of Border Lines Building (Study Case In The Highway Pajajaran Bogor City)) \\ Lucky Viasari ${ }^{1}$, Prima Jiwa Osly ${ }^{1}$ \\ ${ }^{1}$ Program Studi Teknik Sipil Universitas Pancasila \\ E-mail : luckyviasari@gmail.com
}

\begin{abstract}
ABSTRAK
Perkembangan pertumbuhan perekonomian di Kota Bogor yang semakin meningkat membawa dampak bagi pemenuhan akan lahan dan bangunan guna memenuhi aktivitas perkotaan terutama pada Jalan Raya Pajajaran Kota Bogor yang terdapat pada pusat kota yang akan mempengaruhi rencana tata ruang pada setiap bangunan dan menyebabkan ketidaksesuaian Garis Sempadan Bangunan khususnya pada muka bangunan dengan Peraturan Daerah yang berlaku. Selain mengurangi estetika, dapat pula mengganggu dan membahayakan para pengguna jalan yang akan melintas. Penelitian ini dilakukan untuk menganalisis ketidaksesuaian Garis Sempadan Bangunan yang ada terhadap Peraturan Daerah yang sedang berlaku. Pengolahan data dilakukan dengan menggunakan software guna mempermudah dalam penentuan batas bangunan dari setiap bangunan dan batas luar jalan dimana selanjutnya akan digunakan untuk menghitung panjang Garis Sempadan Bangunan di setiap bangunan yang ada dan dianalisis dengan Peraturan Daerah yang berlaku. Hasil akhir didapat bahwa semua bangunan pada studi kasus tidak sesuai dengan Peraturan Daerah yang ada, dimana rata-rata bangunan yang melanggar yaitu $14 \%$ atau sebesar \pm 16 meter dari as jalan. Ditinjau dari banyaknya ketidaksesuaian penulis memberikan rekomendasi yaitu dilakukannya perubahan Peraturan Daerah yang ada sesuai dengan kebijakan yang berlaku.
\end{abstract}

Kata Kunci: Garis Sempadan, Bangunan, Kota Bogor

\section{ABSTRACT}

The development of the economic growth in Bogor increasing bring an impact for fulfillment will land and buildings in order to meet the activity of urban especially on highway Pajajaran Bogor which is found in the city center that will affect the spatial plans at every building and cause nonconformity border lines building particularly in the face of a building with local regulation applicable. Besides reducing aesthetic, it could also disrupt and endanger road users who will pass. This research is to analysis of border lines on buildings bylaws are being enacted. Data processing was done using software to ease in building determination of the limits of any buildings and the outer boundary of the road where next will be used to calculate long border lines building in every existing building and analyzed with local regulation applicable. The final result obtained that all building at case studies not according to rule regional government where the average building that violate is $14 \%$ or by \pm 16 yards from the middle of the road. Judging from the number of offense the authors provide recommendations that the existing changes in existing Regional Regulations in accordance with applicable policies.

Keywords: Border Lines, Building, Bogor City 


\section{PENDAHULUAN}

Kota Bogor merupakan salah satu kota yang mengalami perkembangan sangat cepat di Jawa Barat. Hal tersebut dapat diidentifikasi dari tingginya pemenuhan kebutuhan akan lahan dan bangunan untuk mewadahi aktivitas kota, mulai dari aktivitas perdagangan, industri, pendidikan hingga peruntukan yang lebih luas yaitu pemukiman. Dinamika pertumbuhan yang terjadi di Kota Bogor, dalam kaitannya dengan pemanfaatan ruang di sepanjang ruas jalan khususnya letak bangunan-bangunan yang tidak sesuai dengan rencana tata ruang kenyataan dari kondisi yang ada saat ini, telah berpengaruh pada lebar jalan yang ada: jarak antara bangunan dengan batas jalan di beberapa ruas jalan yang telah tercipta rata-rata terlalu dekat, berhimpit, atau bahkan melewati batas jalan padahal pemerintah telah menetapkan peraturan untuk batas bangunan atau garis sempadan bangunan. Hal ini tentunya akan mempengaruhi keselamatan dari pengguna jalan itu sendiri.

Di dalam Undang-Undang Republik Indoneia No. 28 Tahun 2002 Tentang Bangunan Gedung pasal 13 ayat 1 bagian (b) menyebutkan jarak antara bangunan gedung dengan batas-batas persil, dan jarak antara as jalan dan pagar halaman yang diizinkan pada lokasi yang bersangkutan. Maka dari itu garis sempadan (muka) bangunan/ GSB yaitu merupakan jarak dinding terluar bangunan/batas persil bagian depan terhadap jalan. Jika pada bagian muka bangunan atau pada depan bangunan tersebut adalah jalan satu arah, maka hitungan batas as jalan untuk garis sempadan adalah sampai ujung jalan. Sedangkan jika pada depan bangunan tersebut merupakan jalan dua arah, maka hitungan batas as jalan berada di bagian tengah jalan atau pada median jalan.

Guna mempermudah pengerjaan dalam pengolahan data, untuk penelitian ini menggunakan aplikasi yang bebasis Sistem Informasi Geografis (SIG). Sistem Informasi Geografis merupakan sebuah sistem atau teknologi berbasis komputer yang dibangun de ngan tujuan untuk mengumpulkan, menyimpan, mengolah dan menganalisa, serta menyajikan data dan informasi dari suatu objek atau fenomena yang berkaitan dengan letak atau keberadaannya dipermukaan bumi. (Setianingrum, 2014)

Penelitian ini mempunyai maksud untuk menganalisis ketidaksesuaian keadaan Kota Bogor mengenai batas garis sempadan bangunan khususnya pada Jalan Raya Pajajaran, Kota Bogor. Adapun tujuan pada penelitian ini ialah untuk mengklasifikasi jenis bangunan pada masing-masing bangunan, menganalisis ketidaksesuaian garis sempadan dan Peraturan Daerah yang berlaku dan menganalisis penerapan Peraturan Daerah terhadap Garis Sempadan Bangunan yang berlaku. Penulisan ini dibatasi hanya untuk menganalisis seberapa jauh tingkat ketidaksesuaian garis sempadan yang terjadi pada masing-masing bangunan di sepanjang Jalan
Raya Pajajaran, Kota Bogor tanpa meninjau ulang berdasarkan ketentuan yang berlaku.

\section{METODE}

Penelitian ini dilakukan pengumpulan data terlebih dahulu, yaitu berupa data survey lapangan atau ground check, data citra ikonos Jalan Raya Pajajaran Kota Bogor, peta RBI (Rupa Bumi Indonesia) untuk peta geografis Jalan Raya Pajajaran dan Peraturan Daerah Kota Bogor yang sedang berlaku. Data survey lapangan/ground check digunakan untuk menentukan titik bangunan dan batas jalan yang selanjutnya digunakan untuk pengolahan data untuk mendapatkan data klasifikasi bangunan dan panjang GSB untuk setiap bangunan. Data tersebut selanjutnya akan di analisis dengan Peraturan Daerah yang berlaku untuk mengetahui kesesuaian eksisting nya. Jika tidak sesuai maka akan diberikan pelanggaran atau rekomendasi kepada Pemerintah Kota Bogor agar dilakukannya perubahan Peraturan Darah Kota Bogor yang berlaku mengenai Garis Sempadan Bangunan berdasarkan kepadatan bangunan dan kecepatan kendaraan yang berada di sepanjang ruas jalan tersebut.

\section{STUDI KASUS}

Lokasi penelitian berada pada salah satu jalan utama yang sering dilalui di Kota Bogor yaitu Jalan Raya Pajajaran. Jalan Raya Pajajaran ini memiliki panjang \pm $6 \mathrm{~km}$ dan berbatasan dengan daerah Kedunghalang dibagian utara dan daerah Tajur dibagian selatan.

\section{PETA LOKASI PENELITIAN}

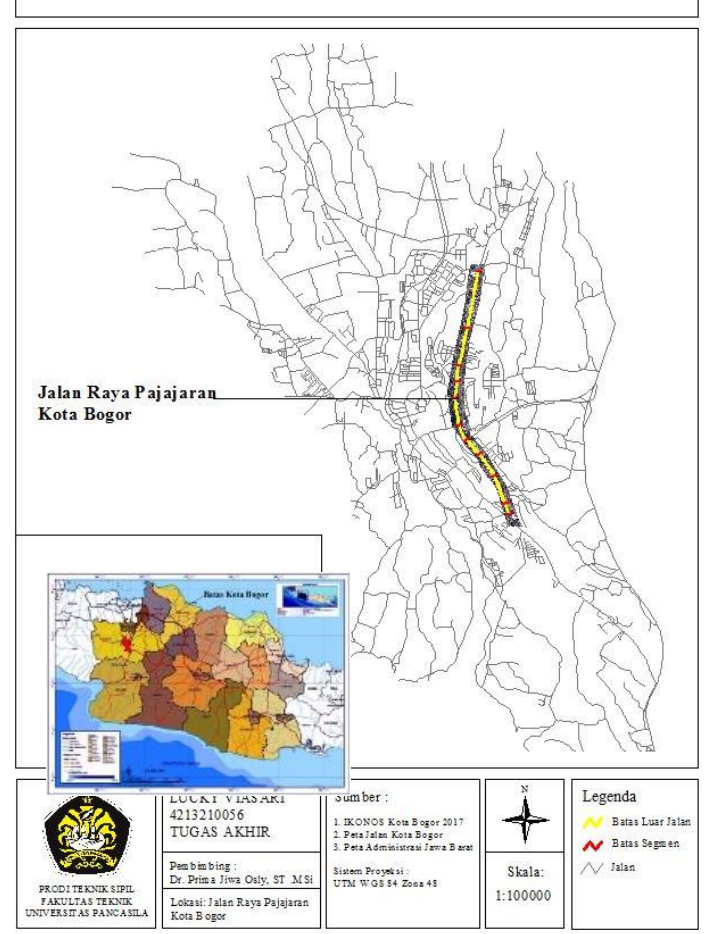

Gambar 1. Peta Lokasi Penelitian. 


\section{Perda Kota Bogor Mengenai Klasifikasi Jenis Bangunan dan GSB}

Pada Berita Daerah Kota Bogor Tahun 2006 Nomor 1 seri C Peraturan Walikota Bogor Nomor 2 Tahun 2006 Tentang Garis Sempadan Bangunan (GSB) dan Garis Sempadan Saluran (GSS) pasal 4 ayat 3 menyatakan bahwa Jalan Raya Pajajaran ini merupakan Jalan arteri primer dimana perhitungan untuk GSB nya yaitu 31 meter dihitung dari as jalan atau 16 meter dihitung dari batas Damaja.

Tabel 1. Perda Kota Bogor mengenai GSB untuk Jalan Raya Pajajaran.

\begin{tabular}{|c|c|c|c|}
\hline \multirow{2}{*}{$\begin{array}{c}\text { Nama } \\
\text { Jalan }\end{array}$} & \multirow{2}{*}{ Jenis Jalan } & \multicolumn{2}{|c|}{ GSB (meter) } \\
\cline { 3 - 4 } & $\begin{array}{c}\text { Dari As } \\
\text { Jalan }\end{array}$ & $\begin{array}{c}\text { Dari Batas } \\
\text { Damaja }\end{array}$ \\
\hline $\begin{array}{l}\text { Jalan Raya } \\
\text { Pajajaran }\end{array}$ & $\begin{array}{l}\text { Jalan Arteri } \\
\text { Primer }\end{array}$ & 31 & 16 \\
\hline
\end{tabular}

Dimana pada Peraturan Daerah Kota Bogor Nomor 8 Tahun 2011 Tentang Rencana Tata Ruang Wilayah Kota Bogor 2011-2031, mengatakan bahwa pada daerah sempadan bangunan ini dapat dimanfaatkan sebagai Ruang Terbuka Hijau (RTH) atau dimanfaatkan untuk kegiatan dalam penanaman pohon tidak digunakan untuk mendirikan bangunan.

Pada Peraturan Daerah yang sama untuk klasifikasi bangunan, dimana dikatakan bahwa Jalan Raya Pajajaran merupakan jalan arteri primer. Pada peraturan tersebut pula menyatakan bahwa untuk jalan arteri primer tidak diperbolehkannya terdapat hypermarket atau pusat perbelanjaan pada sepanjang jalan tersebut. Sedangkan untuk bangunan yang melanggar maka akan dikenakan sanksi sesuai dengan peraturan yang berlaku.

\section{Survey Lapangan/Ground Check}

Survey lapangan ini dimaksudkan untuk mengetahui kesesuaian eksisting atau berapa banyak ketidaksesuaian yang terjadi mengenai batas dari sempadan muka bangunan pada lokasi penelitian dan untuk mengetahui batas dari bangunan tersebut secara nyata dilapangan. Data ini selanjutnya akan digunakan dalam pengolahan data menentukan batas luar jalan dan titik bangunan.

\section{Pembagian Segmen}

Pembagian segmen ini digunakan untuk mempermudah dalam melakukan pengolahan data selanjutnya yaitu untuk mengklasifikasi dan mengitung panjang garis sempadan (GSB) di setiap bangunan pada sepanjang ruas jalan tersebut. Dalam membagi atau memotong setiap segmen, pembagian berdasarkan persimpangan yang berada pada sepanjang ruas jalan pada studi kasus untuk penelitian ini dimana terdapat 10 segmen yang telah dibagi berdasarkan ketentuan tersebut.

\section{Analisis Klasifikasi Jenis Bangunan}

Sebelum menghitung panjang garis sempadan bangunan hal yang perlu diketahui yaitu jenis bangunan yang terdapat pada studi kasus untuk penelitian ini. Hal ini dimaksudkan untuk mengetahui bangunan apa saja yang sesuai ataupun tidak sesuai dengan Peraturan Daerah Kota Bogor mengenai GSB itu sendiri.

Dalam mengklasifikasi jenis bangunan yang ada pada penelitian ini berpedoman pada Peraturan Menteri Pekerjaan Umum No. 29/PRT/M/2006 Tentang Pedoman Persyaratan Teknis Bangunan Gedung Namun untuk analisis ini, tidak dicantumkannya seluruh klasifikasi yang ada pada peraturan tersebut, namun hanya mencantumkan bangunan yang terdapat pada jalan ini yang dibagi menjadi dua bagian yaitu bagian kanan dan bagian kiri. Berikut merupakan batas bangunan dari setiap bangunan beserta klasifikasi jenis bangunan yang ada pada studi kasus penelitian ini.

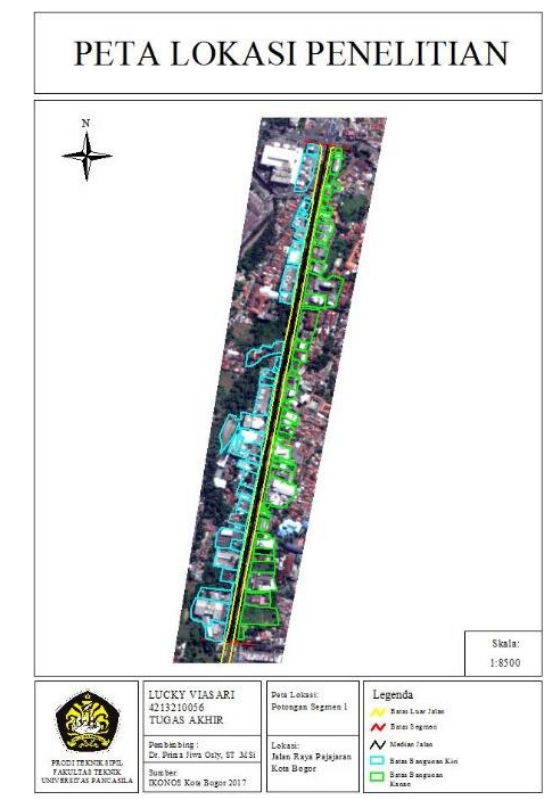

Gambar 2. Peta Lokasi Penelitian Dengan Batas Bangunan Segmen 1.

Jumlah seluruh bangunan yang berada pada segmen 1 yaitu terdapat 88 bangunan dengan bangunan yang mendominasi terdapat pada klas 6 yaitu Bangunan Gedung Perdagangan 


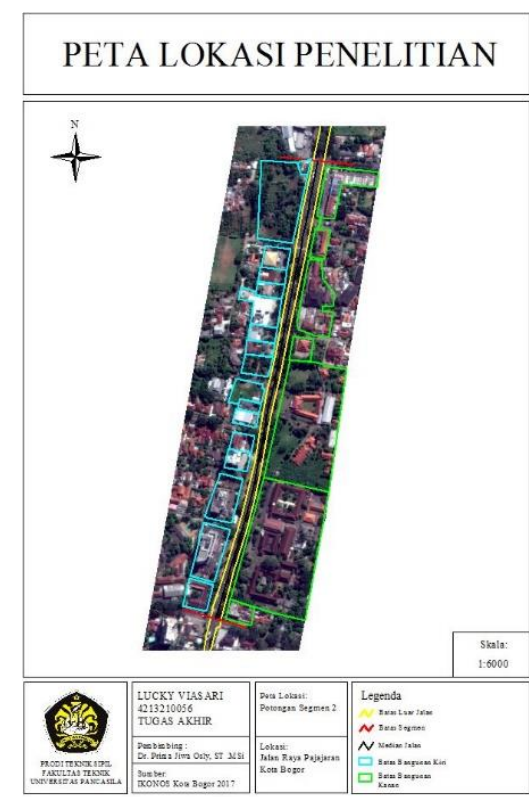

Gambar 3. Peta Lokasi Penelitian Dengan Batas Bangunan Segmen 2.

Jumlah seluruh bangunan yang berada pada segmen 2 yaitu terdapat 23 bangunan dengan bangunan yang mendominasi terdapat pada klas 6 yaitu Bangunan Gedung Perdagangan

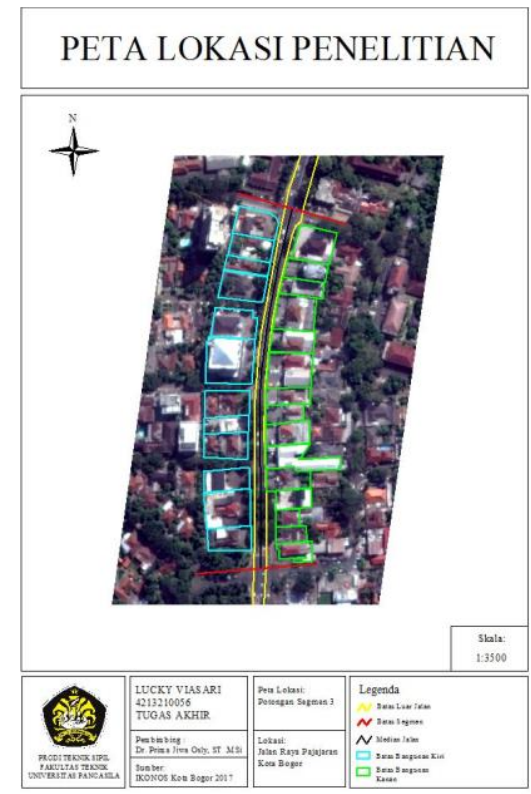

Gambar 4. Peta Lokasi Penelitian Dengan Batas Bangunan Segmen 3.

Jumlah seluruh bangunan yang berada pada segmen 3 yaitu terdapat 27 bangunan dengan bangunan yang mendominasi yaitu Bangunan Gedung untuk Pendidikan pada klas $9 \mathrm{~b}$.

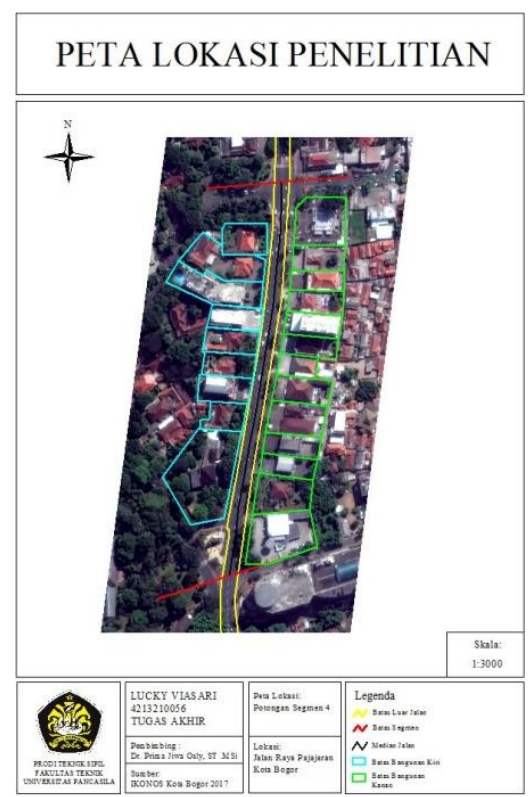

Gambar 5.Peta Lokasi Penelitian Dengan Batas Bangunan Segmen 4.

Jumlah seluruh bangunan yang berada pada segmen 4 yaitu terdapat 22 bangunan dengan bangunan yang mendominasi terdapat pada klas 6 yaitu Bangunan Gedung Perdagangan

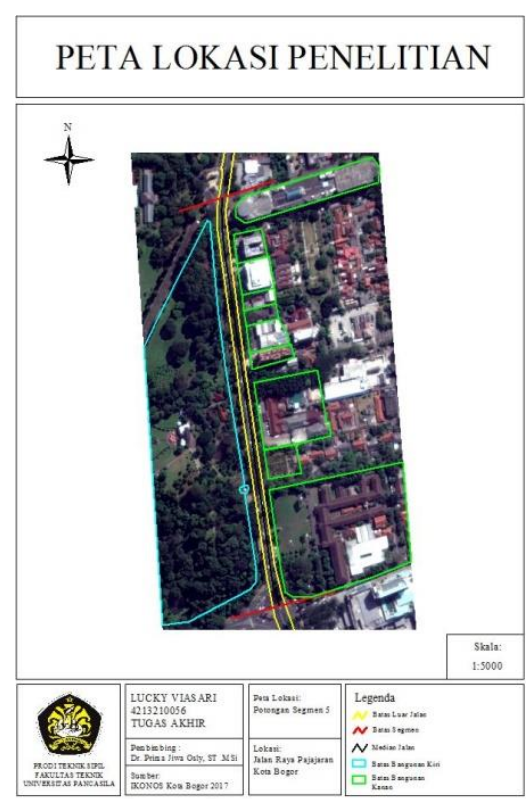

Gambar 6. Peta Lokasi Penelitian Dengan Batas Bangunan Segmen 5.

Jumlah seluruh bangunan yang berada pada segmen 5 yaitu terdapat 12 bangunan dengan bangunan yang mendominasi yaitu Hotel /Wisma /Rumah Dinas pada klas 5. Pada segmen ini terdapat 1 Gedung Pusat Perbelanjaan yaitu Lippo Plaza Bogor pada segmen 5 bagian kanan. 


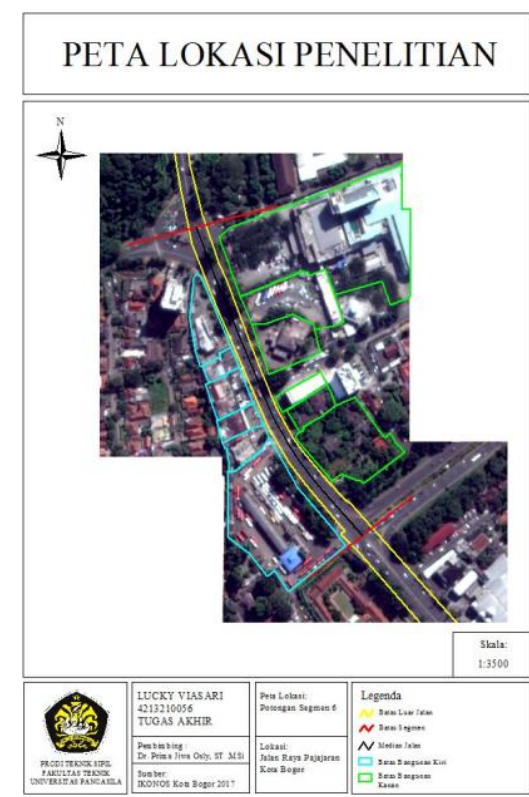

Gambar 7. Peta Lokasi Penelitian Dengan Batas Bangunan Segmen 6.

Jumlah seluruh bangunan yang berada pada segmen 6 yaitu terdapat 12 bangunan dengan bangunan yang mendominasi terdapat pada klas 6 yaitu Bangunan Gedung Perdagangan. Pada segmen ini terdapat 1 Gedung Pusat Perbelanjaan yaitu Botani Square pada segmen 6 bagian kanan.

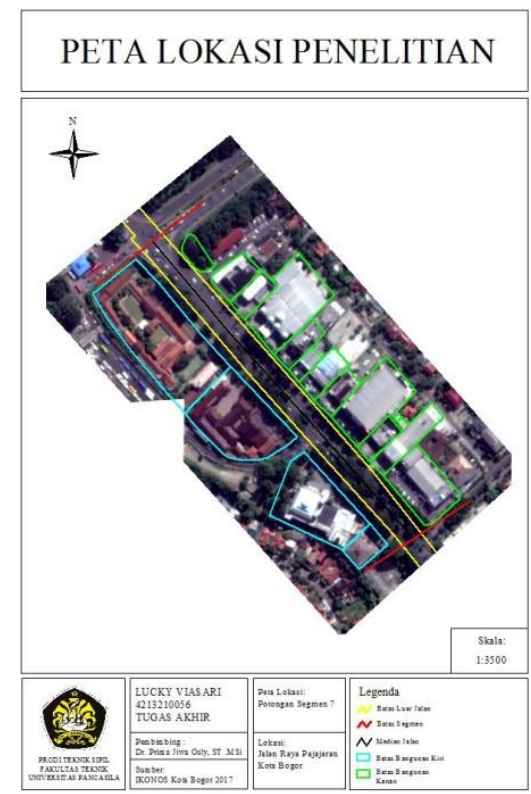

Gambar 8. Peta Lokasi Penelitian Dengan Batas Bangunan Segmen 7.

Jumlah seluruh bangunan yang berada pada segmen 7 yaitu terdapat 16 bangunan dengan bangunan yang mendominasi terdapat pada klas 6 yaitu Bangunan Gedung Perdagangan. Pada segmen ini terdapat 2 Gedung Pusat Perbelanjaan yaitu Ada Swalayan dan Giant Express pada segmen 7 bagian kanan.

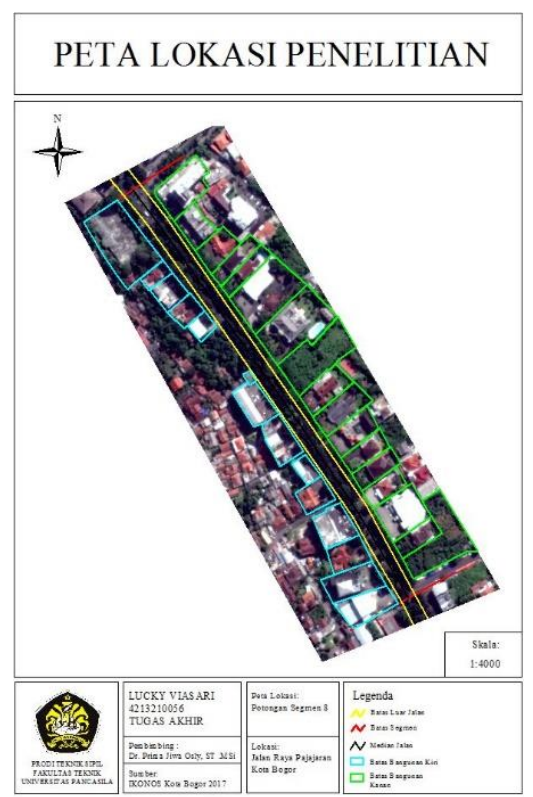

Gambar 9. Peta Lokasi Penelitian Dengan Batas Bangunan Segmen 8.

Jumlah seluruh bangunan yang berada pada segmen 8 yaitu terdapat 31 bangunan dengan bangunan yang mendominasi yaitu Bangunan Gedung Hunian Biasa pada klas 1. Dan jumlah seluruh bangunan yang berada pada segmen 9 yaitu terdapat 40 bangunan dengan bangunan yang mendominasi terdapat pada klas 6 yaitu Bangunan Gedung Perdagangan

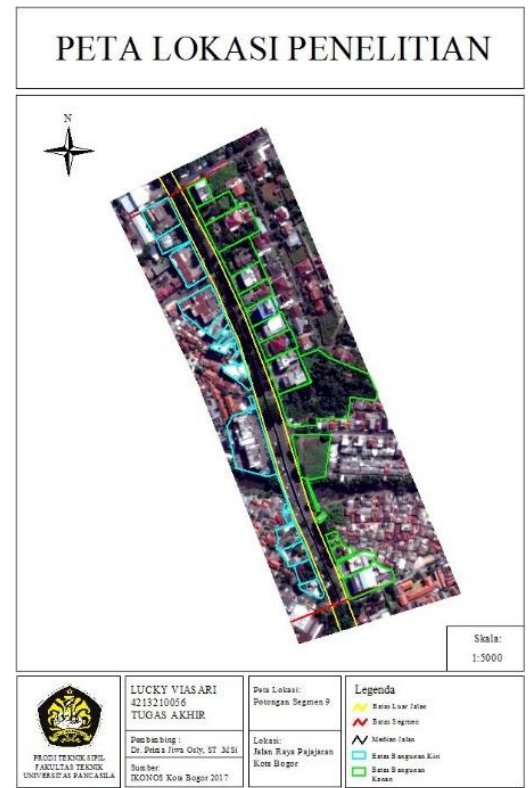

Gambar 10. Peta Lokasi Penelitian Dengan Batas Bangunan Segmen 9. 


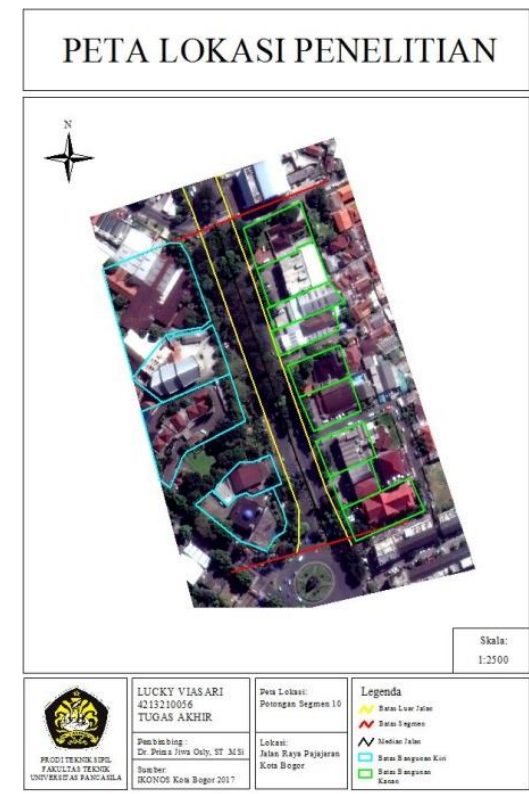

Gambar 11. Peta Lokasi Penelitian Dengan Batas Bangunan Segmen 10.

Jumlah seluruh bangunan yang berada pada segmen 10 yaitu terdapat 14 bangunan dengan bangunan yang mendominasi yaitu Bangunan Gedung Perbelanjaan pada klas 6 . Total dari seluruh bangunan yang berada pada sepanjang ruas Jalan Raya Pajajaran ini yaitu terdapat 285 bangunan dan terdapat 4 pusat perbelanjaan/Hypermarket dibeberapa segmen pada sepanjang ruas jalan tersebut.

Tabel 2. Klasifikasi Bangunan Seluruh Segmen.

\begin{tabular}{|c|c|c|c|}
\hline Lokasi & $\begin{array}{c}\text { Total } \\
\text { Bangunan }\end{array}$ & Klas & Jenis Bangunan \\
\hline $\begin{array}{l}\text { Segmen } \\
1 \text { Kanan }\end{array}$ & 49 & 6 & $\begin{array}{l}\text { Bangunan } \\
\text { Gedung } \\
\text { Perdagangan }\end{array}$ \\
\hline $\begin{array}{l}\text { Segmen } \\
1 \text { Kiri }\end{array}$ & 39 & 6 & $\begin{array}{c}\text { Bangunan } \\
\text { Gedung } \\
\text { Perdagangan }\end{array}$ \\
\hline$\underset{\text { Kanan }}{\text { Segmen2 }}$ & 7 & $9 b$ & $\begin{array}{c}\text { Bangunan } \\
\text { Gedung Untuk } \\
\text { Pendidikan }\end{array}$ \\
\hline $\begin{array}{c}\text { Segmen } \\
2 \text { Kiri }\end{array}$ & 16 & - & 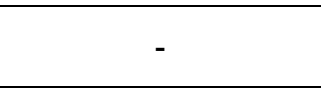 \\
\hline $\begin{array}{l}\text { Segmen } \\
3 \text { Kanan }\end{array}$ & 15 & 6 & $\begin{array}{l}\text { Bangunan } \\
\text { Gedung } \\
\text { Perdagangan }\end{array}$ \\
\hline $\begin{array}{l}\text { Segmen } \\
3 \text { Kiri }\end{array}$ & 12 & 1 & $\begin{array}{c}\text { Bangunan } \\
\text { Gedung Hunian } \\
\text { Biasa }\end{array}$ \\
\hline $\begin{array}{l}\text { Segmen } \\
4 \text { Kanan }\end{array}$ & 13 & 6 & $\begin{array}{c}\text { Bangunan } \\
\text { Gedung } \\
\text { Perdagangan }\end{array}$ \\
\hline $\begin{array}{c}\text { Segmen } \\
4 \text { Kiri }\end{array}$ & 9 & 3 & $\begin{array}{c}\text { Hotel/Wisma/Rumar } \\
\text { Dinas }\end{array}$ \\
\hline $\begin{array}{l}\text { Segmen } \\
5 \text { Kanan }\end{array}$ & 10 & 3 & $\begin{array}{l}\text { Hotel/Wisma/ } \\
\text { Rumah Dinas }\end{array}$ \\
\hline $\begin{array}{c}\text { Segmen } \\
5 \text { Kiri }\end{array}$ & 2 & $10 b$ & $\begin{array}{c}\text { Pagar/Gapura/ } \\
\text { Taman }\end{array}$ \\
\hline
\end{tabular}

\begin{tabular}{|c|c|c|c|}
\hline $\begin{array}{l}\text { Segmen } \\
6 \text { Kanan }\end{array}$ & 6 & - & - \\
\hline $\begin{array}{l}\text { Segmen } \\
6 \text { Kiri }\end{array}$ & 6 & 6 & $\begin{array}{c}\text { Bangunan } \\
\text { Gedung } \\
\text { Perdagangan }\end{array}$ \\
\hline $\begin{array}{l}\text { Segmen } \\
7 \text { Kanan }\end{array}$ & 12 & - & 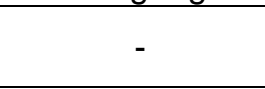 \\
\hline $\begin{array}{l}\text { Segmen } \\
7 \mathrm{Kiri}\end{array}$ & 4 & $9 b$ & $\begin{array}{c}\text { Bangunan } \\
\text { Gedung Untuk } \\
\text { Pendidikan }\end{array}$ \\
\hline $\begin{array}{l}\text { Segmen } \\
8 \text { Kanan }\end{array}$ & 17 & 1 & $\begin{array}{c}\text { Bangunan } \\
\text { Gedung Hunian } \\
\text { Biasa }\end{array}$ \\
\hline $\begin{array}{l}\text { Segmen } \\
8 \text { Kiri }\end{array}$ & 14 & 6 & $\begin{array}{c}\text { Bangunan } \\
\text { Gedung } \\
\text { Perdagangan }\end{array}$ \\
\hline $\begin{array}{l}\text { Segmen } \\
9 \text { Kanan }\end{array}$ & 19 & 6 & $\begin{array}{l}\text { Bangunan } \\
\text { Gedung } \\
\text { Perdagangan }\end{array}$ \\
\hline $\begin{array}{l}\text { Segmen } \\
9 \text { Kiri }\end{array}$ & 21 & 6 & $\begin{array}{l}\text { Bangunan } \\
\text { Gedung } \\
\text { Perdagangan }\end{array}$ \\
\hline $\begin{array}{l}\text { Segmen } \\
10 \text { Kanan }\end{array}$ & 9 & 6 & $\begin{array}{c}\text { Bangunan } \\
\text { Gedung } \\
\text { Perdagangan }\end{array}$ \\
\hline $\begin{array}{c}\text { Segmen } \\
10 \text { Kiri }\end{array}$ & 5 & 5 & $\begin{array}{c}\text { Bangunan } \\
\text { Gedung Kantor }\end{array}$ \\
\hline
\end{tabular}

Untuk klasifikasi bangunan, bangunan paling banyak terdapat pada segmen 1 kanan dengan total bangunan 49 bangunan dan dengan Bangunan Gedung Perdagangan yang mendominasi pada seluruh segmen di sepanjang Jalan Raya Pajajaran Kota Bogor. Pada Peraturan Daerah Kota Bogor Nomor 8 Tahun 2011 Tentang Rencana Tata uang Wilayah Kota Bogor 2011-2031 mengatakan bahwa Jalan Raya Pajajaran merupakan jalan arteri primer, dimana pada jalan arteri primer ini tidak diperbolehkannya terdapat Hypermarket atau Pusat Perbelanjaan. Pada Jalan Raya Pajajaran ini terdapat 4 Pusat Perbelanjaan. Dalam hal klasifikasi pada Jalan Raya Pajajaran ini dapat dikatakan tidak sesuai dengan Peraturan Daerah Kota Bogor Nomor 8 Tahun 2011 Tentang Rencana Tata Ruang Wilayah Kota Bogor 2011-2031 dikarenakan oleh hal tersebut.

\section{Analisis Ketidaksesuaian Garis Sempadan Bangunan Terhadap Peraturan Daerah Kota Bogor}

Didalam Berita Daerah Kota Bogor Tahun 2006 Nomor 1 seri C Peraturan Walikota Bogor Nomor 2 Tahun 2006 Tentang Garis Sempadan Bangunan (GSB) dan Garis Sempadan Saluran (GSS) pasal 4 ayat 3 menyatakan bahwa besaran GSB untuk Jalan Raya Pajajaran yaitu 31 meter dari As Jalan dan 16 meter dari batas Daerah Manfaat Jalan (Damaja). Untuk menganalisis penelitian ini, digunakan panjang GSB dari as jalan yaitu sebesar 31 meter dimana panjang GSB dihitung dari batas tiap bangunan yang telah diklasifikasi oleh olahan data sebelumnya. Berikut merupakan hasil olahan data perhitungan panjang GSB dengan analisis terhadap Perda Kota Bogor. 


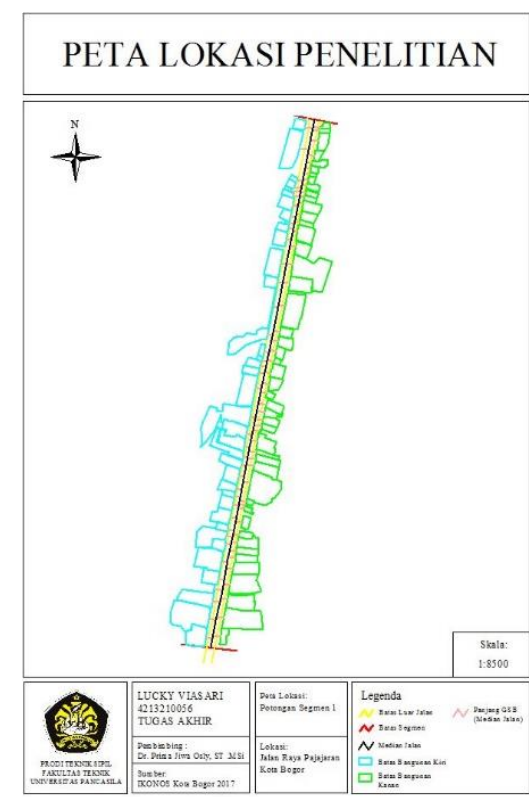

Gambar 12. Peta Lokasi Penelitian Dengan Panjang GSB Segmen 1.

Pada segmen 1 ini terdapat 88 bangunan yang tidak sesuai dengan Perda atau melanggar dimana terdapat 49 bangunan pada segmen bagian kanan dan 39 bangunan pada segmen bagian kiri. Pelanggaran maksimum yaitu pada Bangunan Pertokoan dengan persentase pelanggaran yaitu $19 \%$ pada bagian kanan dan pelanggaran minimum terdapat pada Bangunan Pertokoan yaitu $7 \%$ pada bagian kiri.

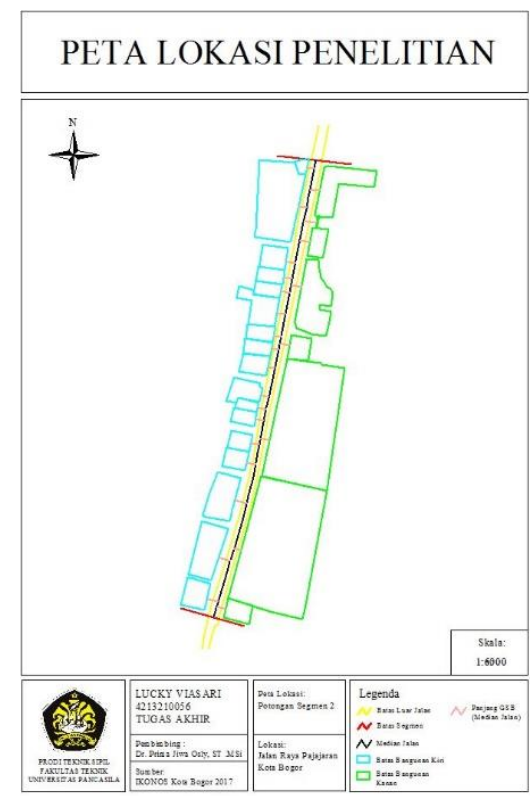

Gambar 13. Peta Lokasi Penelitian Dengan Panjang GSB Segmen 2.

Pada segmen 2 ini terdapat 28 bangunan yang tidak sesuai dengan Perda atau melanggar dimana terdapat 7 bangunan pada segmen bagian kanan dan 16 bangunan pada segmen bagian kiri. Pelanggaran maksimum yaitu pada Bangunan Hotel dengan persentase pelanggaran yaitu $19 \%$ pada bagian kanan dan pelanggaran minimum terdapat pada Bangunan Pagar yaitu $7 \%$ pada bagian kanan.

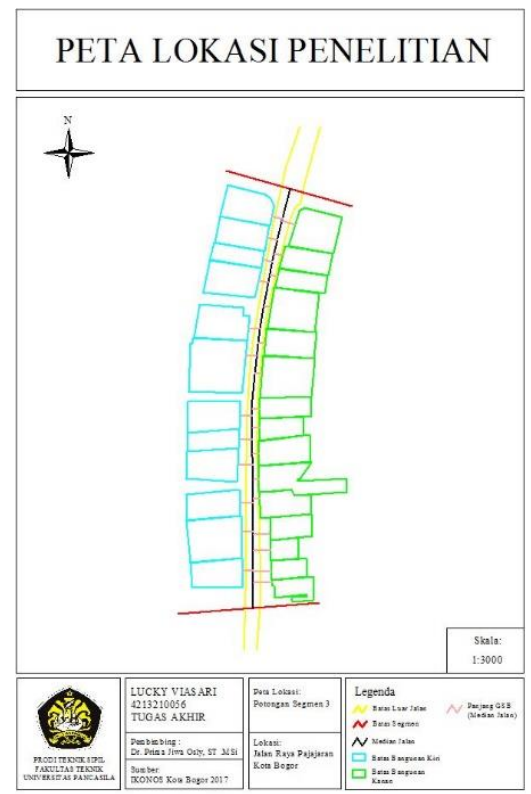

Gambar 14. Peta Lokasi Penelitian Dengan Panjang GSB Segmen 3.

Pada segmen 3 ini terdapat 27 bangunan yang tidak sesuai dengan Perda atau melanggar dimana terdapat 15 bangunan pada segmen bagian kanan dan 12 bangunan pada segmen bagian kiri. Pelanggaran maksimum yaitu pada Bangunan Pertokoan dengan persentase pelanggaran yaitu $25 \%$ pada bagian kanan dan pelanggaran minimum terdapat pada Bangunan Pertokoan pula yaitu $13 \%$ pada bagian kanan.

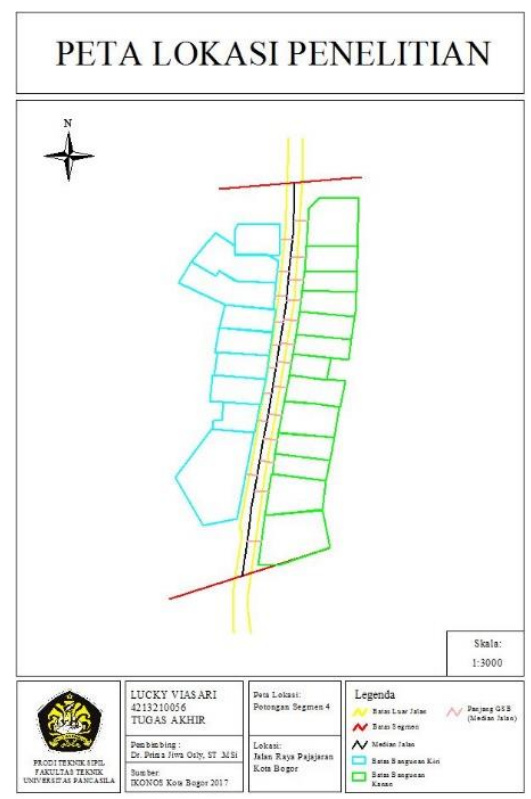

Gambar 15. Peta Lokasi Penelitian Dengan Panjang GSB Segmen 4.

Pada segmen 4 ini terdapat 22 bangunan yang tidak sesuai dengan Perda atau melanggar dimana terdapat 13 bangunan pada segmen bagian kanan dan 9 bangunan pada segmen bagian kiri. Pelanggaran maksimum yaitu pada Bangunan Bank dengan persentase pelanggaran yaitu $23 \%$ pada bagian kiri dan pelanggaran minimum terdapat pada Bangunan Hotel pula yaitu $17 \%$ pada bagian kanan. 


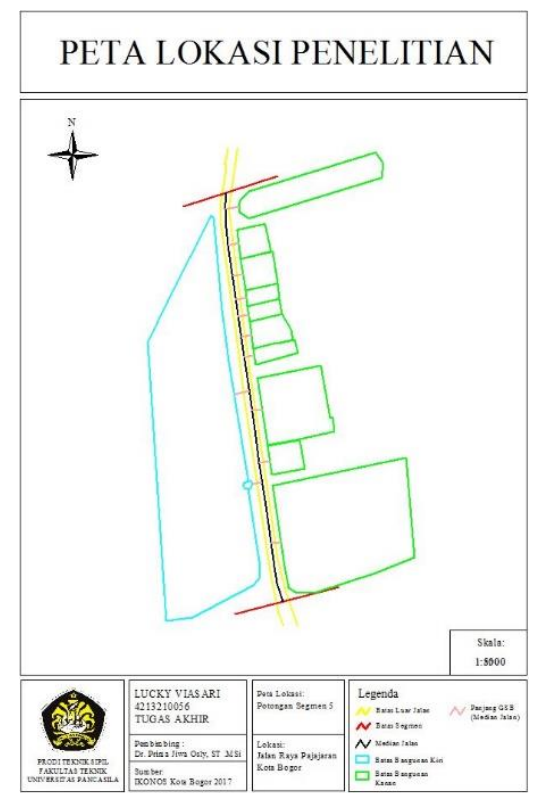

Gambar 16. Peta Lokasi Penelitian Dengan Panjang GSB Segmen 5.

Pada segmen 5 ini terdapat 12 bangunan yang tidak sesuai dengan Perda atau melanggar dimana terdapat 10 bangunan pada segmen bagian kanan dan 2 bangunan pada segmen bagian kiri. Pelanggaran maksimum yaitu pada Bangunan Gedung Kampus IPB dengan persentase pelanggaran yaitu $15 \%$ pada bagian kanan dan pelanggaran minimum terdapat pada Bangunan Pagar pula yaitu $7 \%$ pada bagian kiri.

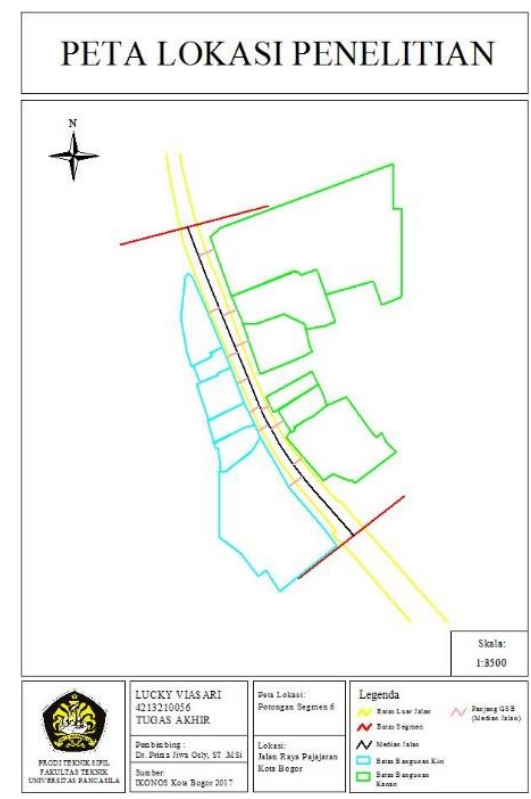

Gambar 17. Peta Lokasi Penelitian Dengan Panjang GSB Segmen 6.

Pada segmen 6 ini terdapat 12 bangunan yang tidak sesuai dengan Perda atau melanggar dimana terdapat 6 bangunan pada segmen bagian kanan dan 6 bangunan pada segmen bagian kiri. Pelanggaran maksimum yaitu pada Bangunan Pertokoan dengan persentase pelanggaran yaitu $19 \%$ pada bagian kiri dan pelanggaran minimum terdapat pada Botani Square pula yaitu $11 \%$ pada bagian kanan.

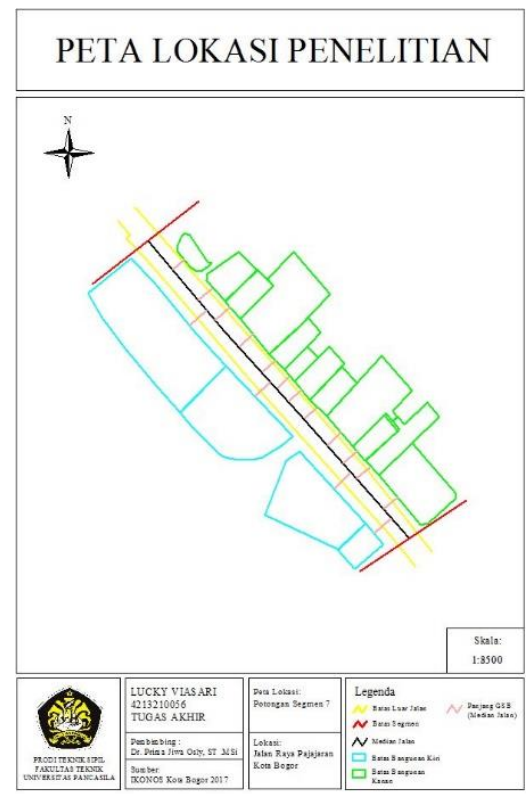

Gambar 18. Peta Lokasi Penelitian Dengan Panjang GSB Segmen 7.

Pada segmen 7 ini terdapat 16 bangunan yang tidak sesuai dengan Perda atau melanggar dimana terdapat 12 bangunan pada segmen bagian kanan dan 4 bangunan pada segmen bagian kiri. Pelanggaran maksimum yaitu pada Taman dengan persentase pelanggaran yaitu $14 \%$ pada bagian kanan dan pelanggaran minimum terdapat pada SMK Baranangsiang yaitu $5 \%$ pada bagian kiri.

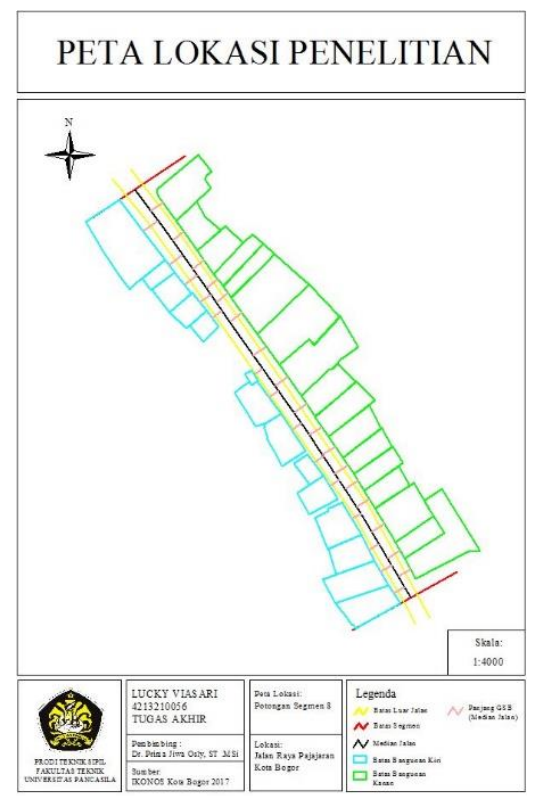

Gambar 19. Peta Lokasi Penelitian Dengan Panjang GSB Segmen 8.

Pada segmen 8 ini terdapat 16 bangunan yang tidak sesuai dengan Perda atau melanggar dimana terdapat 17 bangunan pada segmen bagian kanan dan 14 bangunan pada segmen bagian kiri. Pelanggaran maksimum yaitu pada Bangunan Pertokoan dengan persentase pelanggaran yaitu $18 \%$ pada bagian kiri dan pelanggaran minimum terdapat pada Kantor Reservoir Kebakaran yaitu 8\% pada bagian kiri. 


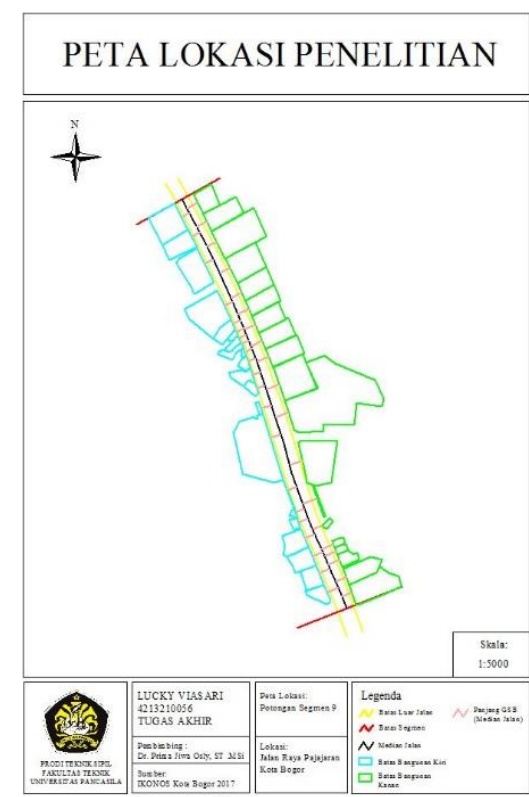

Gambar 20. Peta Lokasi Penelitian Dengan Panjang GSB Segmen 9.

Pada segmen 9 ini terdapat 40 bangunan yang tidak sesuai dengan Perda atau melanggar dimana terdapat 19 bangunan pada segmen bagian kanan dan 21 bangunan pada segmen bagian kiri. Pelanggaran maksimum yaitu pada Bangunan Rumah Makan dengan persentase pelanggaran yaitu $18 \%$ pada bagian kiri dan pelanggaran minimum terdapat pada Pagar yaitu $7 \%$ pada bagian kanan.

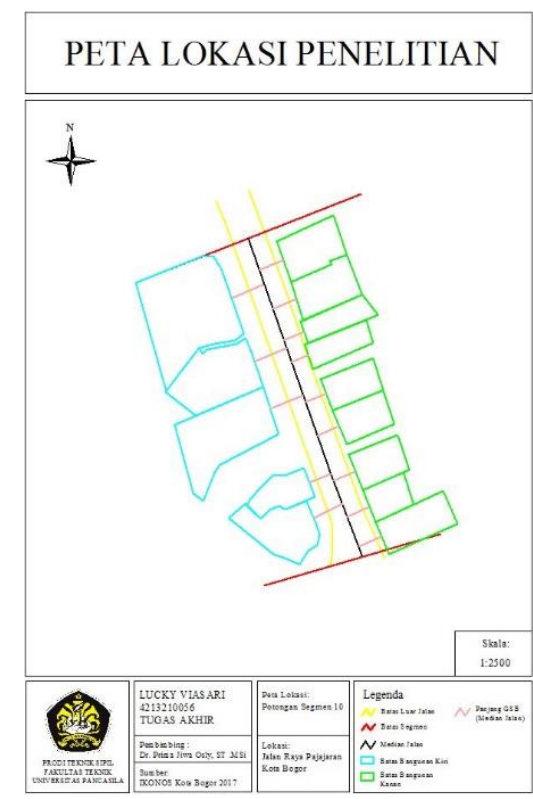

Gambar 21. Peta Lokasi Penelitian Dengan Panjang GSB Segmen 10.

Pada segmen 10 ini terdapat 14 bangunan yang tidak sesuai dengan Perda atau melanggar dimana terdapat 9 bangunan pada segmen bagian kanan dan 5 bangunan pada segmen bagian kiri. Pelanggaran maksimum yaitu pada Bangunan Bengkel Mobil dengan persentase pelanggaran yaitu $16 \%$ pada bagian kanan dan pelanggaran minimum terdapat pada Kantor PDAM yaitu 3\% pada bagian kiri.
Tabel 2. Hasil Analisa Ketidaksesuaian GSB Untuk Seluruh Segmen.

\begin{tabular}{|c|c|c|c|}
\hline Lokasi & $\begin{array}{c}\text { Total } \\
\text { Pelanggaran }\end{array}$ & $\begin{array}{c}\% \text { Min. } \\
\text { Pelanggaran }\end{array}$ & $\begin{array}{c}\% \text { Maks. } \\
\text { Pelanggaran }\end{array}$ \\
\hline $\begin{array}{l}\text { Segmen } \\
1 \text { Kanan }\end{array}$ & 49 & $10 \%$ & $19 \%$ \\
\hline $\begin{array}{c}\text { Segmen } \\
1 \mathrm{Kiri}\end{array}$ & 39 & $7 \%$ & $19 \%$ \\
\hline $\begin{array}{l}\text { Segmen } \\
2 \text { Kanan }\end{array}$ & 7 & $7 \%$ & $19 \%$ \\
\hline $\begin{array}{l}\text { Segmen } \\
2 \text { Kiri }\end{array}$ & 16 & $7 \%$ & $18 \%$ \\
\hline $\begin{array}{l}\text { Segmen } \\
3 \text { Kanan }\end{array}$ & 15 & $13 \%$ & $25 \%$ \\
\hline $\begin{array}{c}\text { Segmen } \\
3 \text { Kiri }\end{array}$ & 12 & $17 \%$ & $22 \%$ \\
\hline $\begin{array}{l}\text { Segmen } \\
4 \text { Kanan }\end{array}$ & 13 & $17 \%$ & $18 \%$ \\
\hline $\begin{array}{c}\text { Segmen } \\
4 \text { Kiri }\end{array}$ & 9 & $19 \%$ & $23 \%$ \\
\hline $\begin{array}{l}\text { Segmen } \\
5 \text { Kanan }\end{array}$ & 10 & $8 \%$ & $15 \%$ \\
\hline $\begin{array}{c}\text { Segmen } \\
5 \text { Kiri }\end{array}$ & 2 & $7 \%$ & $14 \%$ \\
\hline $\begin{array}{l}\text { Segmen } \\
6 \text { Kanan }\end{array}$ & 6 & $11 \%$ & $19 \%$ \\
\hline $\begin{array}{c}\text { Segmen } \\
6 \text { Kiri }\end{array}$ & 6 & $11 \%$ & $16 \%$ \\
\hline $\begin{array}{l}\text { Segmen } \\
7 \text { Kanan }\end{array}$ & 12 & $10 \%$ & $14 \%$ \\
\hline $\begin{array}{c}\text { Segmen } \\
7 \text { Kiri }\end{array}$ & 4 & $5 \%$ & $7 \%$ \\
\hline $\begin{array}{l}\text { Segmen } \\
8 \text { Kanan }\end{array}$ & 17 & $11 \%$ & $13 \%$ \\
\hline $\begin{array}{c}\text { Segmen } \\
8 \mathrm{Kiri}\end{array}$ & 14 & $8 \%$ & $18 \%$ \\
\hline $\begin{array}{l}\text { Segmen } \\
9 \text { Kanan }\end{array}$ & 19 & $7 \%$ & $14 \%$ \\
\hline $\begin{array}{l}\text { Segmen } \\
9 \text { Kiri }\end{array}$ & 21 & $12 \%$ & $18 \%$ \\
\hline $\begin{array}{l}\text { Segmen } \\
10 \text { Kanan }\end{array}$ & 9 & $10 \%$ & $16 \%$ \\
\hline $\begin{array}{c}\text { Segmen } \\
10 \text { Kiri }\end{array}$ & 5 & $3 \%$ & $12 \%$ \\
\hline
\end{tabular}

Dari seluruh segmen yang telah ditinjau dengan total bangunan pada sepanjang ruas Jalan Raya Pajajaran Kota Bogor yaitu sebanyak 285 bangunan dimana pada setiap bangunan tersebut setelah dianalisis dengan batas Garis Sempadan Bangunan (GSB) pada Peraturan Daerah Kota Bogor dapat dikatakan bahwa batas GSB pada setiap bangunan yang berada pada sepanjang jalan ini tidak ada yang sesuai dengan Peraturan Daerah yang berlaku dimana Peraturan Daerah mengatakan bahwa batas GSB dari Jalan Raya Pajajaran yaitu 31 meter dari as jalan, sedangkan rata-rata GSB pada sepanjang ruas jalan ini yaitu $14 \%$ dari Peraturan Daerah yang berlaku dan rata-rata dengan panjang GSB 16,6 meter dari as jalan. 


\section{Penerapan Peraturan}

Peraturan Daerah Kota Bogor Nomor 8 Tahun 2011 Tentang Rencana Tata Ruang Wilayah Kota Bogor 2011-2031, mengenai pemanfaatan garis sempadan pada bangunan yaitu sempadan pada bangunan dimanfaatkan sebagai Ruang Terbuka Hijau atau untuk kegiatan penanaman pohon. Pada Peraturan Daerah tersebut disebutkan bahwa garis sempadan tidak diperbolehkan untuk mendirikan bangunan. Pada Undang-Undang No.28 Tahun 2002 Tentang Bangunan Gedung, mengatakan bahwa sanksi administratif akan dikenakan kepada setiap pemilik bangunan yang melanggar aturan. Sanksi tersebut berupa:

a. Peringatan tertulis

b. Pembatasan kegiatan bangunan

c. Penghentian sementara atau tetap pekerjaan pelaksanaan

d. Pencabutan izin

e. Perintah pembongkaran bangunan.

Selain itu jika diketahui membangun bangunan melebihi GSB yang telah ditentukan maka akan dikenakan sanksi lain yaitu berupa denda paling banyak 10\% (sepuluh persen) dari nilai bangunan yang sedang atau telah dibangun. Dari pengolahan data yang telah dianalisis dengan Peraturan Daerah di Kota Bogor saat ini mengenai garis sempadan bangunan pada tiap-tiap bangunan yang berada pada sepanjang Jalan Raya Pajajaran, dapat dikatakan bahwa semua bangunan pada ruas jalan tersebut tidak sesuai atau melanggar dengan peraturan yang berlaku. Meninjau dari banyaknya ketidaksesuaian yang terjadi pada penelitian ini, penulis merekomendasikan atau memberikan saran agar dilakukannya perubahan Peraturan Daerah Kota Bogor yang berlaku mengenai Garis Sempadan Bangunan berdasarkan kepadatan bangunan dan kecepatan kendaraan yang berada di sepanjang ruas Jalan Raya Pajajaran Kota Bogor atau Pemerintah Kota Bogor dapat menegaskan kembali agar dibongkarnya setiap bangunan yang melanggar sesuai dengan Peraturan Daerah yang berlaku.

\section{KESIMPULAN}

1. Hasil analisis klasifikasi bangunan: terdapat 285 bangunan dengan bangunan yang mendominasi yaitu Bangunan Gedung Perdagangan pada klas 6 dan terdapat 4 hypermarket atau Pusat Perbelanjaan

2. Hasil analisis GSB: terdapat 285 bangunan yang tidak sesuai Perda Kota Bogor yang belaku mengenai GSB dengan:

- Maksimum persentase pelanggaran: $25 \%$

- Minimum persentase pelanggaran: 3\%

- Rata-rata: $14 \%$

3. Hasil pengolahan data yang telah dianalisis dengan Peraturan Daerah yang berlaku mengatakan bahwa setiap bangunan yang berada pada Jalan Raya Pajajaran Kota Bogor tidak sesuai atau telah melanggar Peraturan Daerah yang berlaku.
Meninjau dari banyaknya ketidaksesuaian yang terjadi pada penelitian ini, penulis memberikan saran atau merekomendasikan agar dilakukannya perubahan Peraturan Daerah Kota Bogor yang berlaku mengenai Garis Sempadan Bangunan berdasarkan kepadatan bangunan dan kecepatan kendaraan yang berada di sepanjang ruas Jalan Raya Pajajaran Kota Bogor atau menegaskan kembali agar dibongkarnya setiap bangunan yang melanggar sesuai dengan Peraturan Daerah yang berlaku.

\section{Ucapan Terima Kasih}

Artikel ini merupakan bagian dari tugas akhir pada Program Studi Teknik Sipil, Universitas Pancasila, dibawah bimbingan Bapak Prima Jiwa Osly, atas ilmunya penulis mengucapkan terimakasih.

\section{REFERENSI}

Berita Daerah Kota Bogor Tahun 2006 Nomor 1 seri C Peraturan Walikota Bogor Nomor 2 Tahun 2006

Peraturan Daerah Kota Bogor Nomor 8 Tahun 2011 Tentang Rencana Tata Ruang Wilayah Kota Bogor 2011-2031

Peraturan Menteri Pekerjaan Umum No. 29/PRT/M/2006 Tentang Pedoman Persyaratan Teknis Bangunan Gedung

Setianingrum, D. R. (2014). Kecamatan, Analisis Kesesuaian Lahan Tambak Menggunakan Sistem Informasi Geografis (Studi Kasus: Kecamatan Brangsong, Kab Kendal, Jawa Tengah). Semarang: Fakultas Teknik, Universitas Diponegoro.

Undang-Undang No.28 Tahun 2002 Tentang Bangunan Gedung 